\title{
Inadvertent Complication of a Pipeline Embolization Device for Treatment with Vertebral Artery Dissecting Aneurysm : Distal Tip Fracture of Delivery Wire
}

\author{
Jung Soo Park, M.D., ${ }^{1}$ Hyo Sung Kwak, M.D., ${ }^{2}$ Jong Myong Lee, M.D. ${ }^{1}$ \\ Departments of Neurosurgery, ${ }^{1}$ Radiology, ${ }^{2}$ Research Institute of Clinical Medicine of Chonbuk National University-Biomedical Research Institute of \\ Chonbuk National University Hospital, Jeonju, Korea
}

\begin{abstract}
Use of the Pipeline embolization device (PED) has increased based on studies about its safety and effectiveness, and new reports that describe perior postprocedural complications are now emerging. We report a rare periprocedural device-related complication that occurred during endovascular treatment with the pipeline embolization device for a dissecting aneurysm on the vertebral artery. A 55-year old woman was admitted due to left medullary infarction, and angiography showed a fusiform dilatation in the left vertebral artery that was suspicious for dissecting aneurysm. Endovascular treatment with PED was planned. Under general anesthesia, the procedure was performed without significant problems and a PED was deployed in an appropriate position. However, in the final step of the procedure, the distal tip of the PED delivery wire became engaged within a small branch of the posterior cerebral artery and fractured. Fortunately, imaging studies after the procedure revealed neither hemorrhagic nor ischemic stroke, and the patient recovered without neurological morbidities except initial symptoms.
\end{abstract}

Key Words : Pipeline embolization device · Aneurysm · Endovascular treatment.

\section{INTRODUCTION}

The Pipeline embolization device (PED) (EV3, Irvine, CA, USA) received Food and Drug Administration approval in 2011 in the US based on the Pipeline for Uncoilable or Failed Aneurysms trial. The use of flow diversion stents for endoluminal repair of complex intracranial aneurysms has steadily risen since then ${ }^{2)}$. Initially the PED received limited approval for the treatment of large and giant wide-neck aneurysm in the internal carotid artery, from the petrous to the superior hypophyseal segments; recently, however, its scope of application has increased from posterior circulation aneurysms to small unruptured aneurysms ${ }^{1,6,12,15)}$. As this device was recently developed, long-term safety results are lacking. Moreover, new device-related complications have emerged.

We report distal tip fracture of the PED delivery wire during the treatment of a vertebral artery fusiform aneurysm as an inadvertent complication and review literature relevant to periprocedural device-related complications.

\section{CASE REPORT}

A 54-year-old woman presented with dysarthria and left-sided hemifacial hypoesthesia. Brain magnetic resonance imaging (MRI) revealed a left medullary infarction and magnetic resonance angiography (MRA) showed fusiform dilatation of the left vertebral artery (Fig. 1). The patient underwent digital subtraction angiography (DSA) that revealed a fusiform aneurysm with a dilated portion measuring $7.5 \times 9.3 \mathrm{~mm}$. The diameters of the inflow and outflow were $3.5 \mathrm{~mm}$ and $2.9 \mathrm{~mm}$ (Fig. 2A).

Because the aneurysm was a symptomatic lesion and a vertebrobasilar fusiform aneurysm can potentially cause significant neurological morbidity, we decided to treat the patient with a PED.

Dual antiplatelet therapy, including $100 \mathrm{mg}$ aspirin and 75 mg clopidogrel, was started 7 days prior to the procedure. Under general anesthesia in the biplane angiography room, right femoral artery access was performed and a 6 Fr Envoy guiding catheter (Cordis, Miami, FL, USA) was placed in the proximal por-

• Received : March 31, 2015 • Revised : April 6, 2015 • Accepted : May 29, 2015

- Address for reprints : Hyo Sung Kwak, M.D.

Department of Radiology, Research Institute of Clinical Medicine of Chonbuk National University-Biomedical Research Institute of Chonbuk National University Hospital, 20 Geonji-ro, Deokjin-gu, Jeonju 54907, Korea

Tel : +82-63-250-2582, Fax : +82-63-272-0481, E-mail : kwak8140@jbnu.ac.kr

- This is an Open Access article distributed under the terms of the Creative Commons Attribution Non-Commercial License (http://creativecommons.org/licenses/by-nc/3.0) which permits unrestricted non-commercial use, distribution, and reproduction in any medium, provided the original work is properly cited. 
tion of the left vertebral artery. Intravenous heparin was given to maintain the activated coagulation time at 250-300 s. Then, under the roadman guidance, a Marksman microcatheter (EV3, Irvine, CA, USA) was advanced into the right posterior cerebral artery (PCA). Subsequently a $3.5 \times 25 \mathrm{~mm}$ PED was unsheathed across the target landing zone. Although we required additional manipulations such as repeated 'pull and push' and rotation of the wire, the proximal end of the PED was successfully opened. Until then, the procedure was uneventful and subsequent DSA demonstrated a completely deployed PED with a fully covered fusiform segment (Fig. 2B). However, during removal of the PED delivery wire, its distal tip engaged with a small branch of the right PCA and fractured (Fig. 2C). Subsequent angiography demonstrated vasospasm and thrombus formation just proximal to the PED. Thrombolysis was performed with abciximab and chemical angioplasty. Fortunately, vasospasm and thrombus were resolved on final DSA and the patient recovered without any further neurological morbidity.

\section{DISCUSSION}

The PED is a low-porosity stent-like, flexible, self-expanding construct designed to treat intracranial aneurysms through flow diversion and endoluminal parent vessel reconstruction ${ }^{8,9,14)}$.
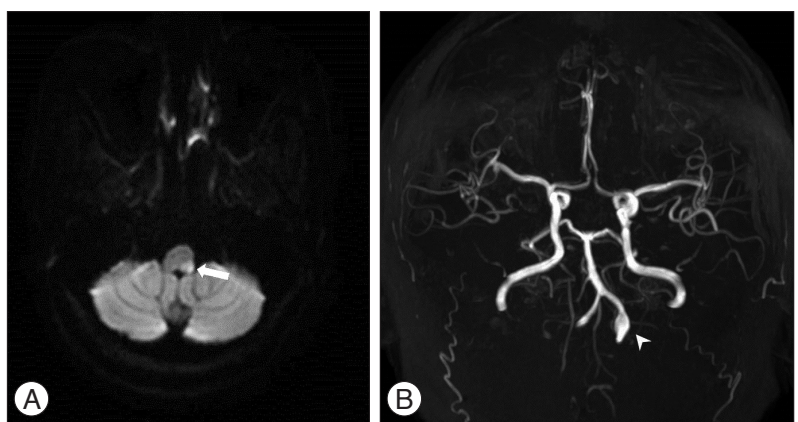

Fig. 1. MRI with diffusion-weighted imaging (A) and MRA (B) demonstrating left medullary infarction (arrow) and fusiform dilatation of the left vertebral artery (arrowhead).
Based on a number of published studies about the efficacy and safety of the PED, the range of application and frequency of use for intracranial aneurysms has increased ${ }^{2,6,12,15,17,18)}$. Recent studies reported that PED has more favorable outcomes in patients with posterior circulation fusiform aneurysms than treatment modalities. Some authors have even recommended PED as a first-line option for unruptured intracranial aneurysms ${ }^{4,9,15,21)}$. However, long-term results are lacking because studies about the PED are often preliminary reports. Moreover, although several large cases series reported acceptable periprocedural complication rates with the PED, periprocedural complications and their management modalities are largely unknown. Besides wellknown traditional complications associated with conventional stents, some case series have presented device-related periprocedural complications due to unique features and handing methods of PED procedures ${ }^{2,6,13,17,19,20)}$.

The PED has a higher metal surface area coverage and elasticity than other currently available self-expanding stents. Due to its elasticity, the PED can shorten from one-half to one-third of its original length ${ }^{10,14)}$. This property makes the PED effective in creating stasis in the aneurysm by increasing the metal surface area coverage. On the other hand, the appropriate deployment position related to the aneurysmal neck and adjacent vessels can be rather unpredictable. Some authors have reported their experiences with migration and shortening of the $\mathrm{PED}^{5,11)}$. They emphasize that accurate PED size is important to confirm adequate apposition to the vessel. In addition, using a longer stent can reduce the conveyance of retrograde force. Technically, instead of going distally and dragging the PED proximally into the landing zone, they preferred to go as close as possible to the landing zone for initial detachment ${ }^{5,6,11)}$. Some cases of unopened proximal or distal edge of stent have been reported. Nabarro et al. ${ }^{16)}$ reported a challenging case that involved opening of the distal part of the PED. They tried repeated manipulation and rotation of the wire, as suggested in the product's instruction for use, and successfully opened it. Ding and Liu' ${ }^{7)}$ reported a case with an unopened, pinched proximal edge of the PED, repre-
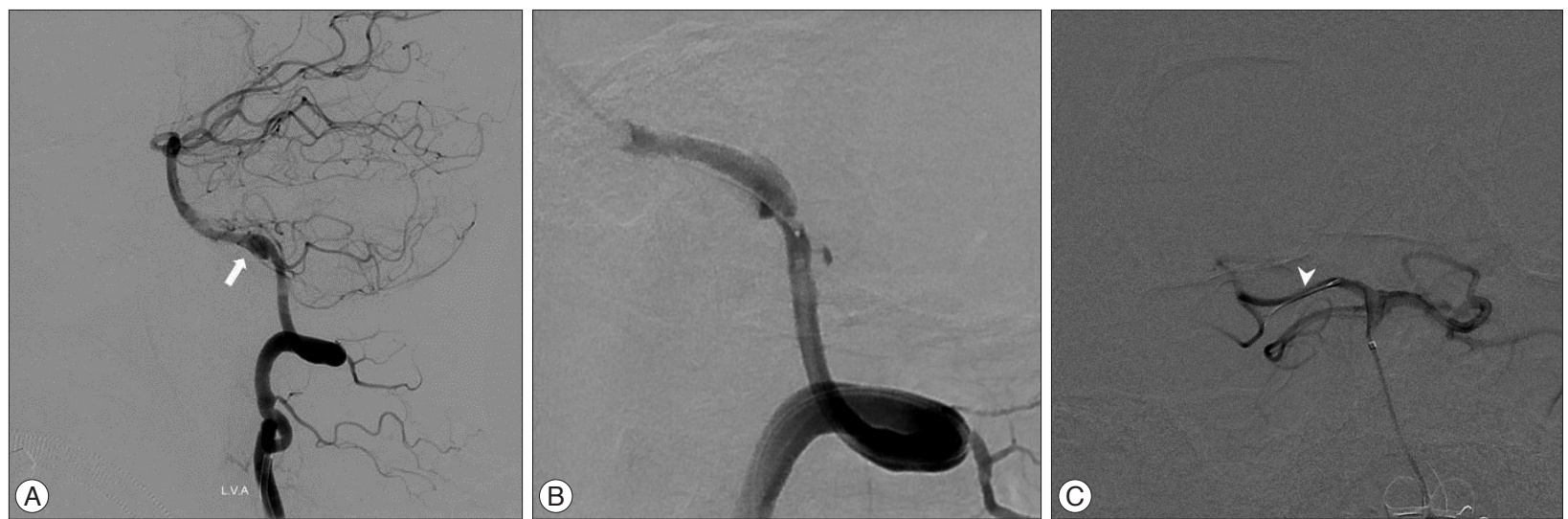

Fig. 2. Distal subtraction angiography during treatment of a vertebral artery fusiform aneurysm with the PED. A : Initial angiography showed a vertebral artery fusiform aneurysm (arrow). B : An angiogram following deployment of the PED showed a fully covered aneurysm. C : A post-procedural angiogram via microcatheter demonstrated a fractured distal tip on the delivery wire (arrowhead). PED : Pipeline embolization device. 
Table 1. Cases of distal tip fracture during the Pipeline embolization device (PED) procedure

\begin{tabular}{llllc}
\hline & Aneurysm location & Initial location of distal tip & Cause of fracture & Complication related fracture \\
\hline Lylyk et al. $^{14)}(2009)$ & NA & NA & $\begin{array}{c}\text { Engaged between the deployed } \\
\text { PED and vessel wall }\end{array}$ & No complication \\
Briganti et al. ${ }^{3)}(2013)$ & SCA & PCA & NA & Thrombus formation \\
Albuquerque et al. ${ }^{1)}(2014)$ & Basilar trunk & PCA & Retained PCA perforator & Thrombus formation \\
Park et al. ${ }^{19)}(2014)$ & Basilar trunk & PCA & Retained PCA perforator & Thrombus formation \\
Present case & VA & PCA & Retained PCA perforator & Thrombus formation
\end{tabular}

NA : date not available, SCA : superior cerebellar artery, PCA : posterior cerebral artery, VA : vertebral artery

senting a thrombogenic complication. We also had trouble with opening of the proximal end of the PED, but fortunately it was opened through a repeated 'push and pull' maneuver and rotation of delivery wire. To our knowledge, there have been five cases of distal coil fracture of the delivery wire including this one (Table 1$)^{1,3,14,19)}$. All these cases except one occurred during treatment of a posterior circulation aneurysm. The distal tip was retained within the perforator of the advanced parent vessel in three cases, and was between the vessel wall and the deployed PED in one case. In our case, repetitive pushing of the delivery wire to the open proximal end of the PED seems to be the major contributor to the engagement of the distal tip within the small perforator. Deploying method of the PED is quite different from conventional unsheathing and deploying method of other self-expanding intracranial stents. The PED require repetitive pushing and pulling of the microcatheter and delivery microwire. In this iterative process, the distal tip might force off and engage in nearby small perforators. This pitfall is particularly relevant in the posterior circulation because the diameters of the PCA or superior cerebellar artery are relatively thin and perforators of nearby parent arteries are not clearly visible. To prevent such a problem, sufficient distal patency for movement of the delivery wire is necessary. In addition, precise observation of blood flow distal to the wire tip and control of the distal delivery wire and through repetitive intraprocedural angiography are essential.

\section{CONCLUSION}

The PED is a feasible and effective method for endoluminal treatment of intracranial aneurysms; however, it requires complex catheter-based skills and has a steeper learning curve than a traditional intracranial self-expanding stent. Even though previous studies have reported an acceptable complication rate, new device-related intraprocedural complications are being reported. To reduce device-related complications, the position of the PED's nearby landing zone and distal access to the device and the tip of the delivery wire should be confirmed through frequent periprocedural angiography.

\section{- Acknowledgements}

This paper was supported by research funds from Chonbuk National University in 2015.

\section{References}

1. Albuquerque FC, Park MS, Abla AA, Crowley RW, Ducruet AF, McDougall CG : A reappraisal of the Pipeline embolization device for the treatment of posterior circulation aneurysms. J Neurointerv Surg 7 : 641-645, 2015

2. Becske T, Kallmes DF, Saatci I, McDougall CG, Szikora I, Lanzino G, et al. : Pipeline for uncoilable or failed aneurysms : results from a multicenter clinical trial. Radiology $267: 858-868,2013$

3. Briganti F, Marseglia M, Leone G, Briganti G, Piccolo D, Napoli M, et al. : Endovascular treatment of a small aneurysm of the superior cerebellar artery with a flow-diverter device. A case report. Neuroradiol J 26 : 327331,2013

4. Chalouhi N, Tjoumakaris S, Dumont AS, Gonzalez LF, Randazzo C, Starke RM, et al. : Treatment of posterior circulation aneurysms with the pipeline embolization device. Neurosurgery $72: 883-889,2013$

5. Chalouhi N, Tjoumakaris SI, Gonzalez LF, Hasan D, Pema PJ, Gould G : Spontaneous delayed migration/shortening of the pipeline embolization device : report of 5 cases. AJNR Am J Neuroradiol 34 : 2326-2330, 2013

6. Chalouhi N, Zanaty M, Whiting A, Tjoumakaris S, Hasan D, Ajiboye N, et al. : Treatment of ruptured intracranial aneurysms with the pipeline embolization device. Neurosurgery $76: 165-172,2015$

7. Ding D, Liu KC : Microsurgical extraction of a malfunctioned pipeline embolization device following complete deployment. J Cerebrovasc Endovasc Neurosurg $15: 241-245,2013$

8. Fiorella D, Lylyk P, Szikora I, Kelly ME, Albuquerque FC, McDougall CG : Curative cerebrovascular reconstruction with the Pipeline embolization device : the emergence of definitive endovascular therapy for intracranial aneurysms. J Neurointerv Surg $1: 56-65,2009$

9. Fiorella D, Woo HH, Albuquerque FC, Nelson PK : Definitive reconstruction of circumferential, fusiform intracranial aneurysms with the pipeline embolization device. Neurosurgery 62 : 1115-1120, 2008

10. Hauck EF, Natarajan SK, Langer DJ, Hopkins LN, Siddiqui AH, Levy EI : Retrograde trans-posterior communicating artery snare-assisted rescue of lost access to a foreshortened pipeline embolization device : complication management. Neurosurgery $67: 495-502,2010$

11. Jabbour P, Chalouhi N, Tjoumakaris S, Gonzalez LF, Dumont AS, Randazzo C, et al. : The Pipeline Embolization Device : learning curve and predictors of complications and aneurysm obliteration. Neurosurgery 73: 113-120; discussion 120, 2013

12. Kallmes DF, Hanel R, Lopes D, Boccardi E, Bonafé A, Cekirge S, et al. : International retrospective study of the pipeline embolization device : a multicenter aneurysm treatment study. AJNR Am J Neuroradiol 36 : 108-115, 2015

13. Keskin F, Erdi F, Kaya B, Poyraz N, Keskin S, Kalkan E, et al. : Endovascular treatment of complex intracranial aneurysms by pipeline flow-diverter embolization device : a single-center experience. Neurol Res 37 : 359-365, 2015

14. Lylyk P, Miranda C, Ceratto R, Ferrario A, Scrivano E, Luna HR, et al. : Curative endovascular reconstruction of cerebral aneurysms with the pipeline embolization device : the Buenos Aires experience. Neurosur- 
gery 64 : 632-642; discussion 642-643; quiz N6, 2009

15. Munich SA, Tan LA, Keigher KM, Chen M, Moftakhar R, Lopes DK : The Pipeline Embolization Device for the treatment of posterior circulation fusiform aneurysms : lessons learned at a single institution. J Neurosurg $121: 1077-1084,2014$

16. Navarro R, Yoon J, Dixon T, Miller DA, Hanel RA, Tawk RG : Retrograde trans-anterior communicating artery rescue of unopened Pipeline Embolization Device with balloon dilation : complication management. J Neurointerv Surg $7: e 7,2015$

17. Nelson PK, Lylyk P, Szikora I, Wetzel SG, Wanke I, Fiorella D : The pipeline embolization device for the intracranial treatment of aneurysms trial. AJNR Am J Neuroradiol 32 : 34-40, 2011

18. Oh SY, Kim MJ, Kim BS, Shin YS : Treatment for giant fusiform aneurysm located in the cavernous segment of the internal carotid artery us- ing the pipeline embolization device. J Korean Neurosurg Soc 55 : 3235,2014

19. Park MS, Albuquerque FC, Nanaszko M, Sanborn MR, Moon K, Abla AA, et al. : Critical assessment of complications associated with use of the Pipeline Embolization Device. J Neurointerv Surg 7 : 652-659, 2015

20. Szikora I, Berentei Z, Kulcsar Z, Marosfoi M, Vajda ZS, Lee W, et al. : Treatment of intracranial aneurysms by functional reconstruction of the parent artery : the Budapest experience with the pipeline embolization device. AJNR Am J Neuroradiol 31 : 1139-1147, 2010

21. Yu SC, Kwok CK, Cheng PW, Chan KY, Lau SS, Lui WM, et al. : Intracranial aneurysms : midterm outcome of pipeline embolization device--a prospective study in 143 patients with 178 aneurysms. Radiology 265 : 893-901, 2012 